\title{
In vivo wear determination of novel CAD/ CAM ceramic crowns by using 3D alignment
}

\author{
Akın Aladağ ${ }^{1 *}$, Didem Oğuz', Muharrem Erhan Çömlekoğlu' ${ }^{1}$, Ender Akan² \\ ${ }^{1}$ Department of Prosthodontics, Faculty of Dentistry, Ege University, Izmir, Turkey \\ ${ }^{2}$ Department of Prosthodontics, Faculty of Dentistry, İzmir Katip Çelebi University, Izmir, Turkey
}

PURPOSE. To determine wear amount of single molar crowns, made from four different restoratives, and opposing natural teeth through computerized fabrication techniques using 3D image alignment. MATERIALS AND METHODS. A total of 24 single crowns ( $N=24$ patients, age range: 18 - 50) were made from lithium disilicate (IPS E-max CAD), lithium silicate and zirconia based (Vita Suprinity CAD), resin matrix ceramic material (Cerasmart, GC), and dual matrix (Vita Enamic CAD) blocks. After digital impressions (Cerec 3D Bluecam, DentsplySirona), the crowns were designed and manufactured (Cerec 3, DentsplySirona). A dualcuring resin cement was used for cementation (Variolink Esthetic DC, Ivoclar). Then, measurement and recording of crowns and the opposing enamel surfaces with the intraoral scanner were made as well as at the third and sixth month follow-ups. All measurements were superimposed with a software (David-Laserscanner, V3.10.4). Volume loss due to wear was calculated from baseline to follow-up periods with Siemens Unigraphics NX 10 software. Statistical analysis was accomplished by Repeated Measures for ANOVA (SPSS 21) at = .05 significance level. RESULTS. After 6 months, insignificant differences of the glass matrix and resin matrix materials for restoration/enamel wear were observed $(P>.05)$. While there were no significant differences between the glass matrix groups $(P>.05)$, significant differences between the resin matrix group materials $(P<.05)$ were obtained. Although Cerasmart and Enamic were both resin matrix based, they exhibited different wear characteristics.

CONCLUSION. Glass matrix materials showed less wear both on their own and opposing enamel surfaces than resin matrix ceramic materials. [J Adv Prosthodont 2019;11:120-7]

KEYWORDS: In vivo wear; Antagonist wear; Resin matrix ceramic crowns; Glass-ceramic crowns; Contemporary computer-aided design and manufacturing (CAD/CAM)

\section{INTRODUCTION}

Contemporary computer-aided design and manufacturing (CAD/CAM) systems involve a wide range of dental restoration indications such as inlays, onlays, laminate veneers, partial and all-ceramic crowns, fixed dental prostheses (FDP), removable dentures, working model fabrication, maxillofacial prostheses as well as implant superstructures. ${ }^{1}$ Such

\footnotetext{
Corresponding author:

Akın Aladağ

Department of Prosthodontics, Faculty of Dentistry, Ege University,

Bornova 35100, Izmir, Turkey

Tel. +902323880327: e-mail, a.aladag@gmail.com

Received December 21, 2018 / Last Revision March 22, 2019 / Accepted April 17, 2019

(C) 2019 The Korean Academy of Prosthodontics

This is an Open Access article distributed under the terms of the Creative Commons Attribution Non-Commercial License (http://creativecommons. org/licenses/by-nc/4.0) which permits unrestricted non-commercial use, distribution, and reproduction in any medium, provided the original work is properly cited.
}

technologies ease the fabrication of high quality and accuracy restorations while decreasing costs and laboratory related consequences. Among material alternatives, ceramic and hybrid materials are mostly preferred for crowns and FDP with their inherent esthetic advantages besides their biocompatibility. $^{2}$ Since the blocks for computerized manufacturing are industrially produced under high pressure to form pre-sintered or pre-polymerized structures, mechanical and physical properties are enhanced. ${ }^{1}$

Lithium disilicate and lithium silicate and zirconia based glass-ceramic reinforced materials have biphasic structures and their crystalline phase is increased. After machining, the glass block is subjected to a heat treatment to cause precipitation and growth of crystalline within the glass and the ceramic becomes reinforced. These glass-ceramics have improved flexural strength and good optical properties, and are available in various shades and translucencies. Since the crack propagation is limited within the ceramic due to the reinforced crystalline phase, higher occlusal loads are required 
for a complete fracture occurrence when compared to conventional ceramics. ${ }^{3}$

Hybrid ceramics (resin matrix) are another group of advantageous esthetic restoratives. Their nano-sized ceramic particle contents (size less than $100 \mathrm{~nm}$ ) up to $80 \%$ wt together with a polymeric matrix give elasticity similar to the natural tooth. In this group of materials, "polymer-infiltratedceramic-network (PICN)' has a unique structure with two interpenetrating networks of ceramic and polymer (double network hybrid) where the fabrication process requires 2 steps starting with the production of a pre-sintered ceramic network (86\%wt feldspar) followed by conditioning with a coupling agent and infiltration with a polymer (14\%wt) by capillary action. ${ }^{4}$

Physiological and pathological conditions such as mastication and parafunctional occlusion may cause wear of the restoratives as well as the opposing dental tissues leading to a loss in tooth anatomy. Resin matrix ceramics have been known to cause less wear to the opposing dentition when compared with the ceramics; however, since the matrix is a polymer that wears faster than the ceramic part, it may become more abrasive for the antagonist with regard to the conventional ceramics. ${ }^{2}$ In dentistry, a restorative material should be durable against heavy occlusal loads while not causing an undesired wear on the opposing dentition. Hybrid ceramics have been deemed to wear close to natural teeth and show similar deformation capacity. ${ }^{5}$ Furthermore, CAD/CAM resin matrix ceramics can be easily milled and intraorally repaired, and occlusal adjustments and polishing can also be made. ${ }^{6}$ Wear resistance of restorative materials and their abrasive effect on dental tissues depend on several factors such as physical (hardness, fatigue, elastic modulus, flexural strength), structural (components), chemical, and surface finishing.

In the present study, clinical wear amounts of CAD/ CAM generated molar crowns made from 4 different materials and natural opposing teeth were evaluated by a $3 \mathrm{D}$ image alignment method. The aim was to determine the clinical wear behaviour of the recently introduced and widely used optimized ceramic and hybrid digitally processed materials. The null hypothesis of this study was that wear differences would be present among various crown materials and opposing enamel.

\section{MATERIALS AND METHODS}

After Ege University Medical Faculty Ethical Committee Approval (No: 15 - 3/13) was obtained, a total of 24 patients (age range: 18 - 50 years, 11 females, 13 males) who came to Ege University Faculty of Dentistry Department of Prosthodontics Clinics for crown treatment were enrolled in the study. The inclusion criteria were: systemically healthy, no loss of periodontal tissues, and having first molar crown indication with natural opposing tooth present. Patients with severe wear due to parafunctioning and having inadequate endodontic treatment and severe loss of periodontal tissues were excluded from the study. The materials used in the study and their compositions are given in Table 1.

All patients were asked to complete informed consent forms and a total of 28 crowns were placed. 2 patients with 2 crowns did not participate in 3 and 6-month recalls due to address change. One zirconia reinforced lithium silicate crown fractured after 1 month and the replaced resin matrix ceramic crown also fractured including a tooth portion after 1 year. Thus, 24 crowns were subjected to clinical follow-up and wear measurements. No specific dietary advice was given to the patients.

Clinical and radiological evaluations of all participants were made and intraoral photographs were obtained. Occlusal (approx. $1.5-2 \mathrm{~mm}$ ) and axial (approx $1-1.5 \mathrm{~mm}$ ) reductions were made with diamond burs (Acurata, $G+K$ Mahnhardt Dental e.K, Thurmansbang, Germany) in $1 \mathrm{~mm}$ chamfer form at cemento-enamel junction, and therefore no gingival retraction was performed (Fig. 1).

After tooth preparation was complete, intraoral digital impression was made by Bluecam (CEREC 3D, version 4.2, Sirona Dental Systems, Bensheim, Germany) both from the prepared tooth and the opposing natural molar region. Finally, interocclusal digital registration was made from the buccal

Table 1. The materials and their chemical compositions used in the study

\begin{tabular}{|c|c|c|}
\hline All-ceramic system & Composition & Manufacturer \\
\hline IPS e.max CAD (EM) (Lithium disilicate) & $\begin{array}{l}58-80 \% \mathrm{SiO}_{2}, 11-19 \% \mathrm{Li}_{2} \mathrm{O}, 0-13 \% \mathrm{~K}_{2} \mathrm{O}, 0-8 \% \mathrm{ZrO}_{2} \text {, } \\
0-5 \% \mathrm{Al}_{2} \mathrm{O}_{3}\end{array}$ & $\begin{array}{l}\text { IvoclarVivadent AG, } \\
\text { Liechtenstein }\end{array}$ \\
\hline Cerasmart (GC) (Resin matrix ceramic) & $\begin{array}{l}\text { Resin matrix: Bis-MEPP, UDMA, dimethacrylate } \\
\text { Inorganic filler: silica, barium glass (71.0 wt\%) }\end{array}$ & GC Corp., Tokyo, Japan \\
\hline $\begin{array}{l}\text { Suprinity (VS) (Zirconia-reinforced lithium silicate) } \\
\text { (ZLS) }\end{array}$ & $\begin{array}{l}\mathrm{SiO}_{2} 56-64 \%, \mathrm{Li}_{2} \mathrm{O} 15-21 \%, \mathrm{~K}_{2} \mathrm{O} 1-4 \%, \mathrm{P}_{2} \mathrm{O}_{5} 3-8 \%, \\
\mathrm{Al}_{2} \mathrm{O}_{3} 1-4 \%, \mathrm{ZrO}_{2} 8-12 \%, \mathrm{CeO}_{2} \mathrm{O}-4 \% \text {, Pigments } 0-6 \%\end{array}$ & $\begin{array}{l}\text { Vita-Zahnfabrik, } \\
\text { Bad Sackingen, Germany }\end{array}$ \\
\hline $\begin{array}{l}\text { Enamic (VE) (Resin matrix ceramic (polymer- } \\
\text { infiltrated-ceramic-network (PICN)) }\end{array}$ & $\begin{array}{l}\text { Resin matrix: UDMA, TEGDMA } \\
\text { Inorganic filler: feldspar ceramic enriched with aluminum oxide } \\
(86.0 \text { wt\%) }\end{array}$ & $\begin{array}{l}\text { Vita-Zahnfabrik, } \\
\text { Bad Sackingen, Germany }\end{array}$ \\
\hline
\end{tabular}

Bis-MEPP, 2,2-Bis(4- methacryloxypolyethoxyphenyl)propane; TEGDMA, triethylene glycol dimethacrylate; UDMA urethane dimethacrylate) 


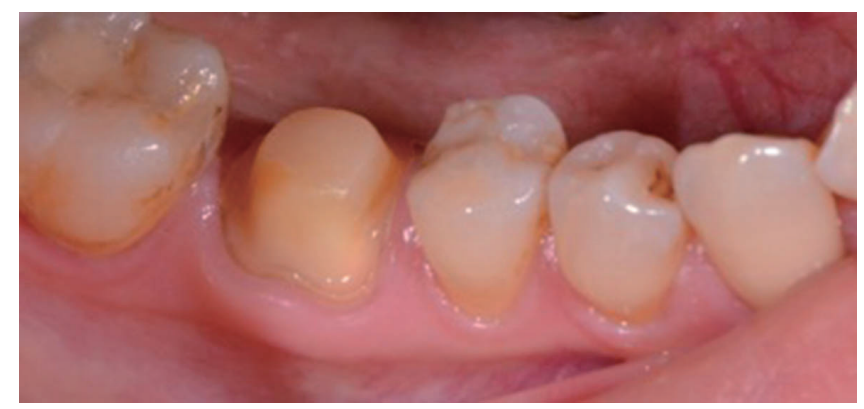

Fig. 1. Tooth preparation in $1 \mathrm{~mm}$ chamfer form at cemento-enamel junction. No gingival retraction was necessary.

aspect. Digital maxillary and mandibular jaw models were aligned according to the digital interocclusal registration. Finish line of the restoration was drawn and the crown design was made.

After a final check of mesial, distal, and occlusal contacts, the crown was milled (Cerec MC XL Premium, Sirona Dental Systems, Bensheim, Germany) from a selected block in appropriate shade (Fig. 2). Crown production stage took approximately $10 \mathrm{~min}$. The patients received 1 type of restorative material randomly selected by drawing of lots method. Internal adaptation of all pre-sintered and resin matrix crowns were checked with a light-body silicone material and required adjustments on occlusal and approximal contacts were made. After try-ins, resin matrix crowns were mechanically polished (GC05 Twist Polisher Kit, Meisinger, Neuss, Germany) and glass-ceramic crowns were fired for crystallization (Vita Vacumat 6000 M, Vita Zahnfabrik, Bad Säckingen, Germany) in accordance with the manufacturers' recommendations. After firing of glass-ceramic crowns, a second try-in was made followed by appropriate staining and glazing procedures in the laboratory. Each type of material was treated in accordance with the manufacturers' instructions before cementation. IPS Emax CAD and Vita Suprinity CAD restorations were etched with $9.5 \%$ hydrofluoric acid (Porcelain Etch, Ultradent, South Jordan, UT, USA) followed by pressurized water cleaning and drying. GC Cerasmart and Vita Enamic restorations were left untreated before cementation. Then all restorations were treated with a silane coupling agent (Monobond Plus, Ivoclar Vivadent AG, Schaan, Liechtenstein) for 60 seconds and air dried.

All crowns were cemented by a dual-curing resin cement (Variolink Esthetic DC, Ivoclar Vivadent AG, Schaan, Liechtenstein). Light-curing was made (Bluephase, Ivoclar Vivadent, Schaan, Liechtenstein) for 40 seconds from each aspect of the restoration. The patient was recalled after 24 hours for occlusion control and corrections where necessary. Then, a digital impression was obtained by the intraoral scanning probe after achieving a complete dry surface by isolation and Cerec Optispray (Sirona Dental Systems
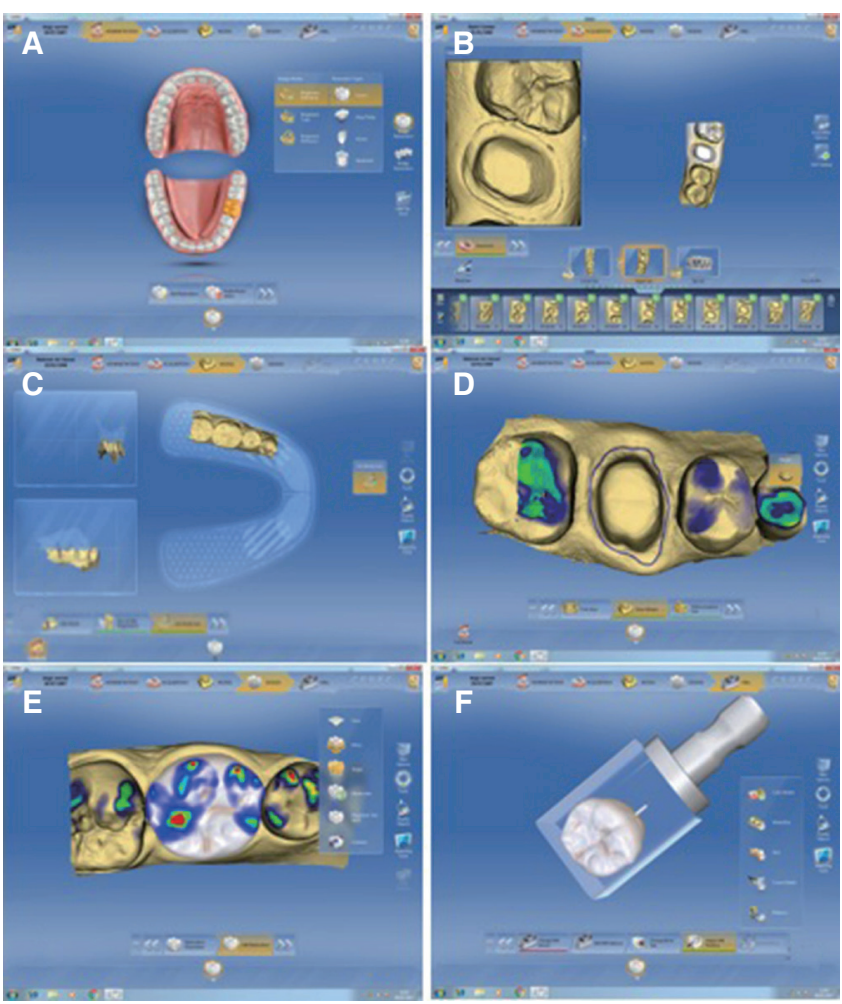

Fig. 2. (A, B) Obtaining digital impression of the prepared tooth and $(\mathrm{C})$ the opposing dentition, (D) determining the finish line of the restoration, (E, F) crown design and arrangement for milling.

$\mathrm{GmbH}$, Bensheim, Germany) application starting from the distal second molar to the mesial second premolar tooth of the cemented crown. The same procedure was applied to the antagonistic jaw where natural first molar in occlusion, second premolar and distal second molar were included to the digital impression by the intraoral scanning probe. Finally, interocclusal digital impression was made from the buccal aspect and the digital jaw model in occlusion was positioned accordingly considering the occlusal plane and Wilson curve. Then, the occlusal contact points of the crowns with the opposing dentition were recorded in the software for further follow-up measurements and comparisons.

Follow-up of the patients were performed for 6 months after cementation of the molar crowns at baseline ( 24 hours after cementation), 3 and 6-month periods. Digital impressions of the crowns and opposing dentition including the mesial and distal teeth regions and interocclusal registrations were obtained following the above mentioned procedures and they were aligned by using the Cerec software (Cerec 4.2, DentsplySirona, Bensheim, Germany). Occlusal contact points on the molars were recorded in the software with a file extension in .rst format.

These recordings were transformed into .stl format by the Cerec InLab software. Then the occlusal thirds of these files were cropped from baseline, 3 and 6-month period dig- 


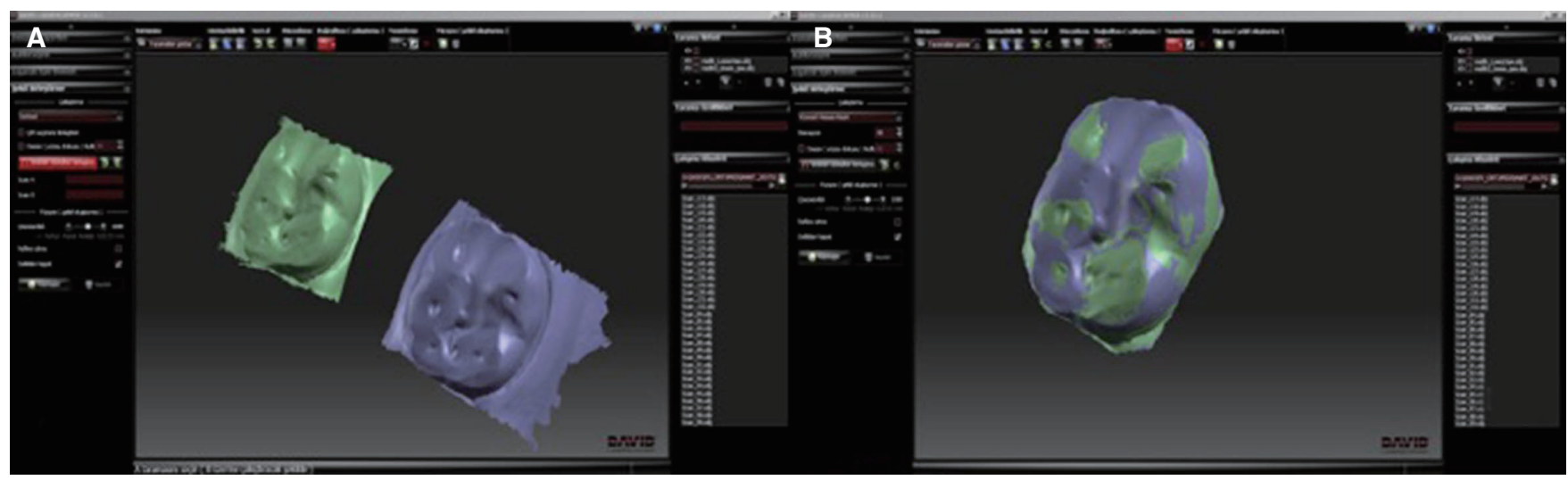

Fig. 3. (A) The cropped images in the laserscanner programme (B) superimposed occlusal images.

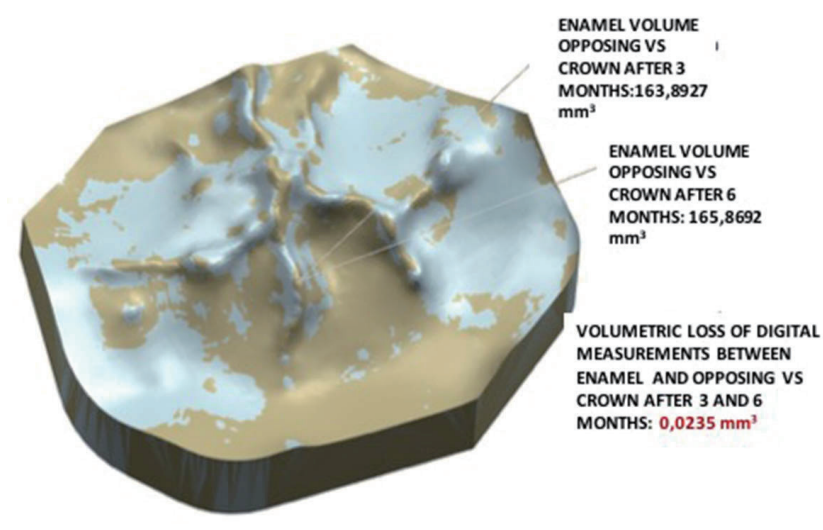

Fig. 4. Volumetric loss calculations by Siemens Unigraphics NX 10 software.

ital impressions and these new digital impressions were superimposed on another software (David-Laserscanner, V3.10.4, Berlin, Germany) (Fig. 3). This software's working principle is that the obtained images are divided into meshes in triangular forms and contacts with the nearest triangular surfaces with a $0.06 \mathrm{~mm}$ tolerance. These superimposed images were then converted into digital solid models by using another software (Siemens Unigraphics NX 10, Siemens PLM Software, Plano, TX, USA). These solid models were put in equal axes and a specific area was chosen on the occlusal surface with a tolerance value of $0.005 \mathrm{~mm}$ and the volumetric loss on the surfaces were calculated for baseline, 3 and 6-month measurements (Fig. 4).

All restorations' and opposing enamel's baseline (0), 3-month and 6-month wear measurements were statistically analyzed (SPSS 21, SPSS Inc., Chicago, IL, USA) at a significance level of 0.05 . Repeated measures for ANOVA test was applied and normality control was obtained by Kolmogorov-Smirnov test $(P=.05)$.

\section{RESULTS}

Mean volumetric wear amounts of the restorative materials and opposing enamel are given in Table 2. The highest amount of wear $\left(\mathrm{mm}^{3} \pm \mathrm{SD}\right)$ was observed on the occlusal surfaces of Cerasmart crowns $(0.31 \pm 0.15)(\mathrm{GC})$ while the least wear amount belonged to Suprinity (0.05 \pm 0.06$)$ (VS). Enamel wear was higher by opposing Enamic (VE) crowns $(0.23 \pm 0.1)$ while lower for Cerasmart crowns $(0.12 \pm$ $0.09)$. The wear differences among the restorations and enamel were insignificant $(P=.9)$. The effect of material type on restoration-enamel wear was significant $(P=.02)$. Differences between materials were insignificant $(P=.1)$.

Mean volumetric wear amounts of the restorative materials and opposing enamel are given in Table 2. The highest mean wear amount belonged to Emax (EM) crowns (0.17 \pm 0.14); however, the mean wear amounts of the other restorative materials were also similar to this value, ranging from 0.09 to 0.14 . The highest enamel wear occurred against GC crowns $(0.21 \pm 0.21)$. The least wear amount among restorative materials belonged to VS $(0.09 \pm 0.07)$; likewise the least enamel wear occurred against VS $(0.07 \pm 0.05)$. The mean differences among the restorative materials' and enamel wear amounts were insignificant $(P=.94)$. The effect of materials on restoration-enamel wear were insignificant $(P=.42)$. The mean wear differences among materials were also insignificant $(P=.44)$.

While the wear amounts of the materials for the first 3 months were different, they did not differ at 6 month leading to statistically insignificant differences.

Mean volumetric wear amounts of the restorative materials and opposing enamel between baseline and 6 months are given in Table 3 . The most wear amount belonged to GC $(0.45 \pm 0.18)$ while the least worn restorative material was VS $(0.14 \pm 0.14)$. The highest enamel wear amount occurred against $\mathrm{VE}(0.39 \pm 0.18)$ while the least wear occurred against EM $(0.26 \pm 0.16)$. The differences among restorative materials and enamel occlusal wear were insignificant $(P=.94)$. The effect of materials on restoration- 
Table 2. Mean volumetric wear amounts of the restorative materials and their opposing enamel for $0-3$ months and 3 6 months

\begin{tabular}{clccccc}
\hline Materials & & $\begin{array}{c}\text { Mean wear }\left(\mathrm{mm}^{3}\right) \\
(0-3 \mathrm{~m})\end{array}$ & SD & $\begin{array}{c}\text { Mean wear }\left(\mathrm{mm}^{3}\right) \\
(3-6 \mathrm{~m})\end{array}$ & SD & $\begin{array}{c}\text { Number of } \\
\text { crowns }\end{array}$ \\
\hline Restoration & EM & 0.093743 & 0.102449 & 0.178314 & 0.140297 & 7 \\
& GC & 0.317533 & 0.154506 & 0.133683 & 0.04452 & 7 \\
& VE & 0.24912 & 0.142566 & 0.14046 & 0.091378 & 5 \\
& VS & 0.05105 & 0.067725 & 0.091275 & 0.074368 & 5 \\
Enamel & & & & & Total: 24 \\
& EM & 0.158886 & 0.157061 & 0.101757 & 0.103038 & 7 \\
& GC & 0.127683 & 0.099608 & 0.211467 & 0.205868 & 7 \\
& VE & 0.23524 & 0.107804 & 0.16084 & 0.085647 & 5 \\
& VS & 0.1998 & 0.109431 & 0.0763 & 0.053577 & 5 \\
& & & & & & Total: 24 \\
\hline
\end{tabular}

Table 3. Mean volumetric wear amounts of the restorative materials and their opposing enamel for 0-6 months

\begin{tabular}{ccccc}
\hline Materials & & $\begin{array}{c}\text { Mean wear } \\
\left(\mathrm{mm}^{3}\right)\end{array}$ & SD & $\begin{array}{c}\text { Number of } \\
\text { crowns }\end{array}$ \\
\hline Restoration & EM & 0.272057 & 0.1589849 & 7 \\
& GC & 0.451217 & 0.1894061 & 7 \\
& VE & 0.38958 & 0.1653977 & 5 \\
& VS & 0.142325 & 0.1412636 & 5 \\
& & & & Total: 24 \\
Enamel & EM & 0.260643 & 0.1657518 & 7 \\
& GC & 0.33915 & 0.1876026 & 7 \\
& VE & 0.39608 & 0.1728979 & 5 \\
& VS & 0.2761 & 0.1366608 & 5 \\
& & & & Total: 24 \\
\hline
\end{tabular}

enamel wear was insignificant $(P=.46)$. The correlation among materials was insignificant $(P=.06)$; however, this result was close to the significance level since all materials exhibited similar wear amounts within themselves. Thus, the materials were divided into 2 main groups (glass and resin matrix ceramics) and subjected further to secondary statistical analysis (Fig. 5).

According to Fig. 5, VS and EM showed lower wear amounts than the enamel while GC and VE resulted in higher wear amounts meaning that similar structured materials could partially exhibit similar wear behavior and that a secondary ANOVA test for repeated measurements was applied to understand the correlation within ceramic groups. The results are given in Table 4 and Table 5 for $0-3,3-6$, and $0-6$ months measurements in terms of ceramic groups.

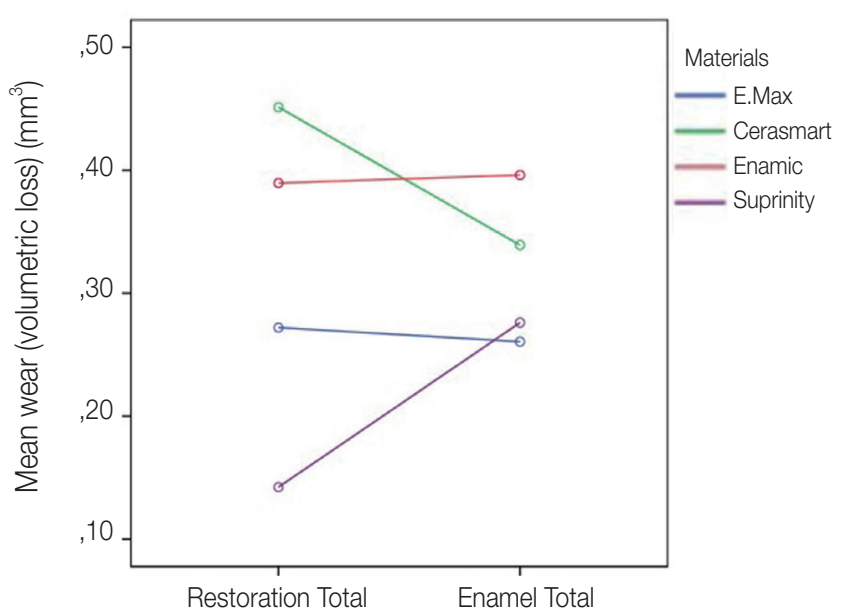

Fig. 5. Total volumetric mean wear among materials and enamel at 6 months.

At 0 - 3 months, the glass-ceramic matrix materials showed lower wear amounts. Although glass-ceramic matrix ceramic groups caused partially less enamel wear, they exhibited similar amounts of enamel wear with the resin matrix ceramic groups (Table 4). The wear amounts between glass-ceramic materials and enamel were insignificant $(P=$ .13). However, the differences between enamel and resin matrix ceramic materials were significant $(P=.01)$. The effect of glass matrix ceramics on restoration-enamel wear was insignificant $(P=.5)$ while resin matrix ceramics had a significant effect $(P=.021)$. The correlation between glass matrix ceramic groups was significant $(P=.001)$ while resin matrix ceramic groups revealed insignificant differences $(P$ $=.07$ )

At 3 - 6 months, although glass-ceramic materials exhib- 
ited approximately twice as much wear within groups, the enamel wear they caused were less than the first 3 months. Resin matrix ceramic groups also exhibited less restoration wear than the first 3 months. However, they revealed differences within the groups (Table 4). The differences among glass ceramic and resin matrix ceramic groups revealed insignificant differences in terms of restoration and enamel wear $(P>.05)$. Both glass matrix and resin matrix ceramic materials showed insignificant differences among groups $(P>.05)$.

At 0 - 6 months, glass matrix ceramic materials caused less opposing enamel wear and restoration than resin matrix ceramic materials (Table 5). VS glass matrix ceramic material caused higher enamel wear while showing less self-wear. EM led to similar wear amount both in itself and on opposing enamel. Both glass matrix ceramic groups exhibited similar enamel wear amounts while VS revealed less self-wear. Among resin matrix ceramic groups, GC revealed higher self-wear while showing less opposing enamel wear. In general, GC was worn more than VE restorations, and VE caused higher opposing enamel wear than GC. The restoration-enamel wear amounts as well as material type's effects on restoration-enamel wear among glass matrix and resin matrix ceramic groups were insignificant $(P>.05)$. While the material correlation between glass matrix ceramic groups were insignificant $(P=.69)$, resin matrix ceramic groups revealed significant differences $(P=.001)$. Although GC and VE belong to the same material group, their wear behaviors differed. Clinical images of the crowns for all material groups and wear measurement periods are given in Figure 6.

Table 4. Mean volumetric wear amounts of the ceramic material groups and opposing enamel for $0-3$ and $3-6$ months

\begin{tabular}{|c|c|c|c|c|c|}
\hline $\begin{array}{l}\text { Ceramic } \\
\text { group }\end{array}$ & Material & & $\begin{array}{c}0-3 \\
\text { months }\end{array}$ & $\begin{array}{c}3-6 \\
\text { months }\end{array}$ & $\begin{array}{l}\text { Number } \\
\text { of crowns }\end{array}$ \\
\hline \multirow[t]{6}{*}{ Glass matrix } & Restoration & EM & 0.093743 & 0.178314 & 7 \\
\hline & & VS & 0.051050 & 0.091275 & 5 \\
\hline & & & & & Total: 12 \\
\hline & Enamel & EM & 0.158886 & 0.101757 & 7 \\
\hline & & VS & 0.199800 & 0.076300 & 5 \\
\hline & & & & & Total: 12 \\
\hline \multirow[t]{6}{*}{ Resin matrix } & Restoration & GC & 0.317533 & 0.133683 & 7 \\
\hline & & VE & 0.249120 & 0.140460 & 5 \\
\hline & & & & & Total: 12 \\
\hline & Enamel & $\mathrm{GC}$ & 0.127683 & 0.211467 & 7 \\
\hline & & VE & 0.235240 & 0.160840 & 5 \\
\hline & & & & & Total: 12 \\
\hline Total & & & & & 24 \\
\hline
\end{tabular}

\section{DISCUSSION}

In this in vivo study, wear behavior of CAD/CAM fabricated crowns with differing chemical compositions were compared. Since the effect of restorative material on time-related restoration and/or opposing enamel wear was found to be significant, the null hypothesis of the study was accepted.

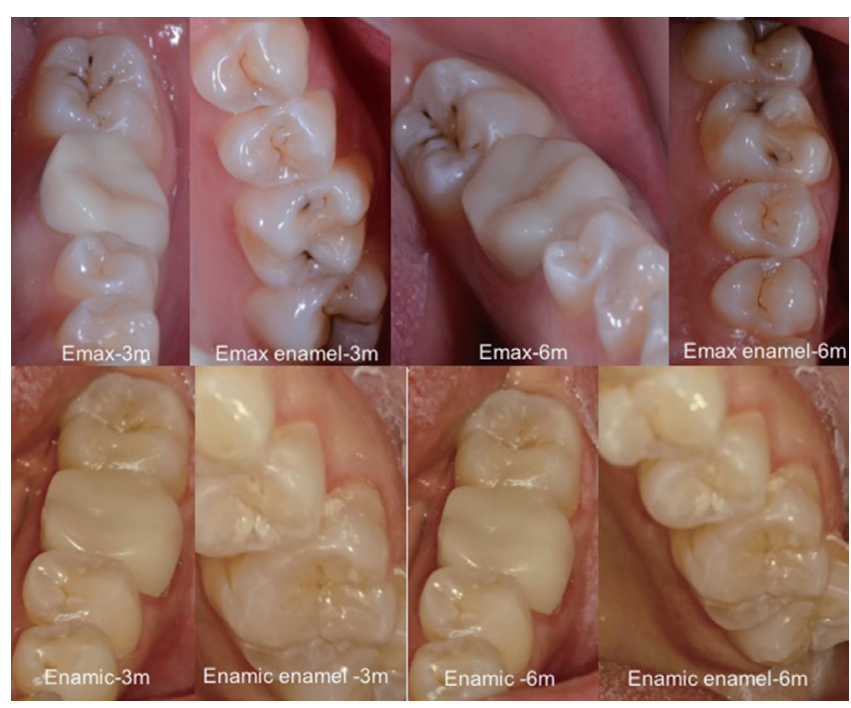

Fig. 6. Cemented crowns and their clinical situations at 3 and 6-month intervals.

Table 5. Mean volumetric wear amounts of the ceramic material groups and opposing enamel for 0 - 6 months

\begin{tabular}{llcccc}
\hline $\begin{array}{l}\text { Ceramic } \\
\text { group }\end{array}$ & Material & & $\begin{array}{c}\text { Mean wear } \\
\left(\mathrm{mm}^{3}\right)\end{array}$ & SD & $\begin{array}{c}\text { Number } \\
\text { of crowns }\end{array}$ \\
\hline Glass matrix & Restoration & EM & 0.272057 & 0.1589849 & 7 \\
& & VS & 0.142325 & 0.1412636 & 5 \\
& & & & Total: 12
\end{tabular}

$\begin{array}{rrrrr}\text { Enamel } & \text { EM } & 0.260643 & 0.1657518 & 7 \\ & \text { VS } & 0.276100 & 0.1366608 & 5\end{array}$

$\begin{array}{lccccc}\text { Resin matrix Restoration } & \text { GC } & 0.451217 & 0.1894061 & 7 \\ & & \text { VE } & 0.389580 & 0.1653977 & 5 \\ & & & & & \text { Total: } 12\end{array}$

Enamel $\quad$ GC $\quad 0.339150 \quad 0.1876026 \quad 7$

$\begin{array}{llll}\text { VE } & 0.396080 & 0.1728979 \quad 5\end{array}$

Total: 12

Total 
In conventionally produced ceramic restorations, mechanical and esthetic properties of the restorations are highly affected by laboratory workflow and dental technician's skills and experience. Therefore, the flaws during fabrication stages may risk the adaptation and durability of the restorations. In an in vitro study comparing production methods' quality of traditionally and CAD/CAM fabricated ceramic restorations by electron microscopy, while porosities were observed in powder-liquid mixed and heat-pressed restorations, CAD/CAM generated restorations did not exhibit any porosities. ${ }^{8}$ This was attributed to the fact that internal flaws were not present, or negligible, due to the homogenous production stages of the CAD/CAM blocks. This parameter is important for the adaptation and durability of the restorations. ${ }^{8}$ Another risk factor for all-ceramic restorations are chipping and fracture due to veneering quality of the framework material. This is highly associated with wettability, shrinkage, inadequate surface roughness, interfacial structural flaws as well as mismatch of the thermal expansion coefficients of the framework and veneering ceramics during the production stages. ${ }^{9}$ On the other hand, $\mathrm{CAD} / \mathrm{CAM}$ fabricated monolithic all-ceramic crowns exhibited higher survival rates than conventionally veneered $\mathrm{CAD} /$ CAM fabricated all-ceramic crowns. ${ }^{10}$ Thus, CAD/CAM produced and optimized ceramic materials with differing compositions were selected for the present study in order to eliminate laboratory and technician related risk factors.

Standardization of in vitro studies based on extracted human teeth is difficult due to varying factors such as age, size, anatomy and storage conditions of teeth, and lack of chewing simulation. Although several in vitro tribological tests (such as pin-on-disc mode two-body wear tests) have been offered for measuring wear of dental restoratives, ${ }^{11}$ the ideal way of determining dental restoratives and enamel wear are the clinical trials. However, this may take longer periods to finalize and may be difficult to recall. Considering the importance of in vivo findings, a clinical study was designed in the present study.

Since it has been shown earlier that marginal discrepancy was insignificant for the majority of available all-ceramic systems with rounded shoulder or chamfer preparation design, ${ }^{12}$ chamfer was preferred for the crown preparations in this study. The used digital software also allowed for both rounded shoulder or chamfer preparation designs.

A previous study on the comparison of marginal gap of all-ceramic crowns for intraoral digital impression making versus conventional impression making revealed that the mean marginal gap amount was higher for the conventional group $(71 \mu \mathrm{m})$ than the digital group $(49 \mu \mathrm{m})$. Additionally, the interproximal contact points of the digitally produced crowns were of superior quality. ${ }^{13}$

An earlier study on the comparison of intraoral and extraoral impression making on marginal gap amount showed in significant differences between the two methods. ${ }^{14}$ Thus, all impressions in the present study were obtained by intraoral impression and image making.

The main problem in optical impressions is the 'distal shadow phenomenon' in which the accuracy of the image is affected by the created distal shadow of the ray on the object (herein, tooth) reflected by the camera. This effect can be reduced by increase in crown length and decrease in taper angle. ${ }^{15}$ Nakamura et al. investigated the effect of allceramic crown preparation tapers of $4^{\circ}, 8^{\circ}$, and $12^{\circ}$ on the internal adaptation of restorations fabricated by Cerec 3 system. They found that there were no significant differences in internal adaptation of crown restorations among differing taper angles and the mean internal gap of the crowns varied between 116 and $162 \mu \mathrm{m}$, in accordance with other previous studies. ${ }^{16-19}$ Therefore, all tooth preparations in our study were designed with a $12^{\circ}$ taper angle and $120 \mu \mathrm{m}$ cement gap in Cerec 3 software, thus the distal shadow phenomenon was also reduced.

In the present study, overall, the material correlation between glass matrix ceramic groups was insignificant while resin matrix ceramic groups (GC and VE) revealed significant differences in terms of antagonist enamel wear. This was attributed to the fact that the two materials have different "genetic" structures. Nanoceramic group materials are claimed to have flexural strength (approximately $200 \mathrm{MPa}$ ) and abrasion resistance ( 2 - $10 \mu \mathrm{m}$ per year) similar to natural tooth. However, the matrix is a polymer that will wear faster than the ceramic, making it more abrasive than antagonists compared to traditional ceramics. ${ }^{2}$ Polymer-InfiltratedCeramic-Network (PICN) material (herein Enamic-VE), on the other hand, consists of a hybrid structure with two interpenetrating networks of ceramic and polymer-'double network-hybrid'. During the fabrication process, a porous presintered ceramic network is first produced and then infiltrated with a polymer by capillary action after conditioning by a coupling agent. Therefore, these structural differences result in the above mentioned differing wear patterns of the two resin matrix ceramic group materials in the present study. However, the most abrasive materials for antagonist enamel were the resin matrix ceramic groups rather than glassmatrix ceramic groups, probably because of the earlier abrasion of the polymer parts of these materials whereas their ceramic components did not. Further, the exposed ceramic network parts may have more abrasive effects on enamel.

An earlier in vitro finding was that polished Vita Suprinity specimens were more likely to be worn than the antagonist enamel specimens, ${ }^{18}$ concurrently, in our study, VS crowns were also to a less extent self-worn than enamel followed by EM, VE and GC crowns, respectively.

Since the resin matrix ceramic group materials in the present study revealed higher wear amounts than glass matrix ceramics, we conclude that their polish are rapidly worn. As an example, GC crowns were self-worn higher than the other groups in the first 3 months and their opposing enamel surfaces were less worn. In the second 3-month period, the resin matrix ceramics exhibited higher wear than the glass ceramics. Thus, these findings pointed out to the fact that the abrasive particles after wearing of their polished surfaces had a great role in high enamel wear amounts. Likewise, the manufacturers of the resin matrix 
ceramics recommended intraoral repolishing every 6 months. Therefore, it was concluded that resin matrix ceramics should be polished every 3 months to decrease antagonistic enamel and restoration wear.

\section{CONCLUSION}

In an overall 6-month period, resin matrix ceramics caused higher wear on both restorations and opposing enamel. Glass matrix ceramics revealed less wear than their opposing enamel surfaces. Resin matrix ceramics exhibited differing wear behavior due to their structural differences, and Cerasmart had a higher wear amount. Therefore, a shortened repolishing period can be recommended for resin matrix ceramic restorations.

\section{ORCID}

Muharrem Erhan Çömlekoğlu https://orcid.org/0000-0002-09155821

Ender Akan https://orcid.org/0000-0002-4596-2612

\section{REFERENCES}

1. Strub JR, Rekow ED, Witkowski S. Computer-aided design and fabrication of dental restorations: current systems and future possibilities. J Am Dent Assoc 2006;137:1289-96.

2. Lambert H, Durand JC, Jacquot B, Fages M. Dental biomaterials for chairside CAD/CAM: State of the art. J Adv Prosthodont 2017;9:486-95.

3. Bindl A, Lüthy H, Mörmann WH. Strength and fracture pattern of monolithic CAD/CAM-generated posterior crowns. Dent Mater 2006;22:29-36.

4. Della Bona A, Corazza PH, Zhang Y. Characterization of a polymer-infiltrated ceramic-network material. Dent Mater 2014;30:564-9.

5. Leinfelder KF. Indirect posterior composite resins. Compend Contin Educ Dent 2005;26:495-503.

6. Zhi L, Bortolotto T, Krejci I. Comparative in vitro wear resistance of CAD/CAM composite resin and ceramic materials. J Prosthet Dent 2016;115:199-202.

7. Oh WS, Delong R, Anusavice KJ. Factors affecting enamel and ceramic wear: a literature review. J Prosthet Dent 2002;87: 451-9.

8. Giordano R. Materials for chairside CAD/CAM-produced restorations. J Am Dent Assoc 2006;137:14S-21S.

9. Isgrò G, Pallav P, van der Zel JM, Feilzer AJ. The influence of the veneering porcelain and different surface treatments on the biaxial flexural strength of a heat-pressed ceramic. J Prosthet Dent 2003;90:465-73.

10. Mörmann WH, Bindl A. All-ceramic, chair-side computeraided design/computer-aided machining restorations. Dent Clin North Am 2002;46:405-26.

11. Sajewicz E. On evaluation of wear resistance of tooth enamel and dental materials. Wear 2006;260:1256-61.

12. Quintas AF, Oliveira F, Bottino MA. Vertical marginal discrepancy of ceramic copings with different ceramic materials, finish lines, and luting agents: an in vitro evaluation. J Prosthet Dent 2004;92:250-7.

13. Syrek A, Reich G, Ranftl D, Klein C, Cerny B, Brodesser J. Clinical evaluation of all-ceramic crowns fabricated from intraoral digital impressions based on the principle of active wavefront sampling. J Dent 2010;38:553-9.

14. da Costa JB, Pelogia F, Hagedorn B, Ferracane JL. Evaluation of different methods of optical impression making on the marginal gap of onlays created with CEREC 3D. Oper Dent 2010;35:324-9.

15. Mou SH, Chai T, Wang JS, Shiau YY. Influence of different convergence angles and tooth preparation heights on the internal adaptation of Cerec crowns. J Prosthet Dent 2002;87: 248-55.

16. Nakamura T, Dei N, Kojima T, Wakabayashi K. Marginal and internal fit of Cerec $3 \mathrm{CAD} / \mathrm{CAM}$ all-ceramic crowns. Int J Prosthodont 2003;16:244-8.

17. Björn AL, Björn H, Grkovic B. Marginal fit of restorations and its relation to periodontal bone level. II. Crowns. Odontol Revy 1970;21:337-46.

18. McLean JW, von Fraunhofer JA. The estimation of cement film thickness by an in vivo technique. Br Dent J 1971;131:10711.

19. Daryakenari G, Alaghehmand H, Bijani A. Effect of simulated mastication on the surface roughness and wear of machinable ceramics and opposing dental enamel. Oper Dent 2019;44:88-95. 